\title{
Potential for rubber (Hevea brasiliensis Muell. Arg.) cultivation in the Eastern Province of Sri Lanka
}

\author{
V.H.L. Rodrigo*, S.M.M. Iqbal and R.S. Dharmakeerthi \\ Rubber Research Institute of Sri Lanka, Dartonfield, Agalawatta.
}

Revised: 13 January 2011 ; Accepted: 20 January 2011

\begin{abstract}
Rubber cultivation in Sri Lanka has been confined mainly to the Wet Zone where the extent of land under rubber declined rapidly with urbanization and land fragmentation. Therefore in order to meet the demand for natural rubber cultivation has been undertaken in moderately dry areas (Intermediate Zone) of the country. Lands in the intermediate zone that were previously subjected to shifting cultivation have been targeted for rubber cultivation with collaboration of the peasant community whose livelihood depended largely on seasonal crops grown on these lands. Therefore, benefits of rubber cultivation in those areas are threefold, and include increased rubber production, increased forest cover and improved livelihood of the rural poor. The Eastern Province of the country was selected for the present study. The feasibility of rubber cultivation in this area was examined in three steps. Firstly, a review of available secondary data was conducted, followed by interviews with key informants and site visits to the potential areas. Secondly, rubber plants were established in limited smallholdings of a selected village followed by an agronomic assessment on initial establishment of rubber. Finally a SWOT analysis was conducted in the village.
\end{abstract}

For rubber cultivation in the Eastern Province, the areas under the Intermediate Zone comprising soils predominantly of reddish brown earth and immature brown loams were selected. Initial growth and establishment of rubber in smallholdings showed potential success in rubber cultivation in the region. The mean survival of rubber plants for all sites established was recorded as $75 \%$ together with an annual plant girth expansion rate of $7.44 \mathrm{~cm}$. Land did not appear to be a limiting factor and farmers were highly interested in cultivating rubber in the area concerned. However, problems associated with land ownership needed to be sorted out enabling farmers to obtain current rubber subsidy benefits. Extension programmes were to be strengthened to educate farmers on crop management practices of rubber. Poor roads to villages and lack of finances were the constraints for expansion of rubber cultivation. Timely distribution of planting materials, fertilizer and subsidy payments were essential for proper establishment of rubber.
Measures to be taken to address the problems associated with dry spells and socio-economic needs of the farmers were also identified.

Keywords: Hevea brasiliensis, intercropping, rubber cultivation, rubber smallholder.

\section{INTRODUCTION}

Sri Lanka is the world's $9^{\text {th }}$ (IRSG, 2004) largest producer of natural rubber. The export of rubber, earned foreign exchange of US\$ 51 million in 2004 (Ministry of Plantation Industries, 2005). The industry provided employment to more than 500,000 people (CARP, 1992). Although the world price of natural rubber fell during the latter part of the 1990s, it recovered soon due to the increase in demand for natural rubber and a shortfall in production in major rubber producing countries together with decline in stocks (RSG, 2001a). Global demand for natural rubber is likely to increase further, particularly with increasing consumption in the Asian continent (IRSG, 2001b; Thilakaratne et al., 2002). In Sri Lanka, rubber based industries are booming up with the total amount of foreign exchange earnings from rubber based products being greater than that from raw rubber exports (Central Bank of Sri Lanka, 2003a). However, there is virtually no potential for further expansion of the rubber cultivation in the traditional rubber growing areas, i.e. Wet Zone, due to urbanization and industrialization. Therefore, the government of Sri Lanka has targeted the Intermediate Zone in the south east of the island for future expansion of rubber cultivation. The extent of smallholder rubber cultivation in the Intermediate Zone is presently less than 4000 ha \{unpublished information from the Rubber Development Department $(R D D)\}$ even though rubber was originally grown in this region at the

*Corresponding author (laksh@sltnet.lk) 
time of its introduction to Sri Lanka in 1876 (Amaraweera, 1976). Even though the annual rainfall in the Intermediate Zone is sufficient for growth of rubber, the existence of distinct dry seasons makes quality management practices critical to the successful establishment of the crop when compared to the traditional rubber growing regions in the Wet Zone.

At present, rubber cultivation in the Intermediate Zone is restricted to two main districts; Monaragala and Hambantota with 1907 and 209 rubber smallholders and areas of ca. 3025 and 104 ha, respectively (unpublished information from the regional office of the RDD for Southern region). In these two districts more land is available to be developed as new potential areas for expansion of rubber cultivation.

Eastern Province has currently been targeted for development programmes by the government of Sri Lanka. It comprises large extents of sparsely populated land indicating the potential for establishing plantation crops like rubber. However, suitable areas for rubber cultivation should be identified within the province. In this process, socio-economic and cultural factors associated with rural livelihood need to be assessed together with climatic conditions, before commencing any large scale programme on rubber cultivation. Researchers have hypothesized that there could be many areas suitable for rubber cultivation in the Eastern Province. Therefore, the study reported here was aimed at identifying those areas in the region based on climatic, agronomic, socioeconomic and cultural factors.

\section{METHODS AND MATERIALS}

The study comprised three steps; firstly a rapid appraisal to identify suitable new areas for cultivation of rubber, secondly a preliminary level agronomical assessment of

Table 1: The checklist used in the rapid appraisal to assess initial feasibility of growing rubber in the Eastern Province of Sri Lanka

\begin{tabular}{|cl|}
\hline . & Climatic variability \\
. & Soil characteristics and distribution \\
- & Population livelihood \\
- & Farmers' attitudes on planting rubber \\
- & Land availability for planting rubber \\
- & Existing cropping systems \\
- & Functioning of agricultural societies \\
\hline
\end{tabular}

the newly established plantations of rubber, and finally an analysis based on strengths, weaknesses, opportunities and threats (SWOT) to scrutinize the potential for the expansion of rubber cultivation in the region.

The rapid appraisal was based on the checklist given in Table 1. This was commenced in October, 2003, with an initial review on climatic conditions of Eastern Province using a detailed map on agro-climatic zones of Sri Lanka (Panabokke, 1996; DOA, 2003b). The province comprises basically two zones, the Intermediate Zone and Dry Zone. With the perception that the Intermediate Zone was better for rubber than the Dry Zone, areas under Padiyatalawa and Maha Oya Pradeshiya Sabhas in the Ampara District were identified for a pilot study. Discussions were held with the Divisional Secretaries (DS) of those areas to determine their personal attitudes on planting rubber and to obtain their support for the study. Then, a group of scientists from the Rubber Research Institute of Sri Lanka (RRISL) comprising an ethno-botanist, an agronomist, a soil-scientist and a rubber clone specialist paid a three-day study visit to the relevant area. During this visit, existing soil pits were examined and soil samples were taken for further examination on physical and chemical properties of the soil.

Two villages, namely Komana and Warapitiya, were initially selected from Padiyatalawa and Maha Oya Pradeshiya Sabhas, respectively for agronomic assessment. In each village, three farmers were selected for initial establishment of rubber with the consultation of Divisional Secretaries of the area. The farm lands selected for rubber cultivation had been assigned for growing seasonal crops such as maize. Therefore, rubber was proposed to be planted as an intercropping system with these seasonal crops. Budgrafted polybagged clonal rubber plants from the genotype RRIC121 were distributed among farmers, and advised to do the planting at a spacing of $2.4 \mathrm{~m} \mathrm{X} 8.1 \mathrm{~m}$ with a density of 500 plants per hectare as recommended by the RRISL. The selected farmers in the Warapitiya village lost interest in planting rubber, hence only the farmers in Komana participated in the pilot study. Nevertheless, only two farmers in Komana were able to cultivate rubber due to the problem in the supply of quality planting material. A training programme on initial establishment and maintenance of rubber was conducted among farmers. However, poor knowledge and lack of experience of the farmers on rubber cultivation, and socio-economic constraints resulted in poor management of plots. First planting of rubber was done in October 2003 and thereafter, some additional farmers in the same village and an adjacent village, Helakomana, wanted to be involved in rubber 
cultivation. Hence planting rubber was extended by an additional $4.7 \mathrm{ha}(11.5 \mathrm{ac})$ and $10.8 \mathrm{ha}(26.5 \mathrm{ac})$ of smallholdings in Komana and 3.3 ha (08ac) and 9.8 ha (24ac) in Helakomana in November 2004 and 2005, respectively.

Crop establishment and growth were assessed in May 2006 in terms of percentage of plants survived and the girth of the tree at four feet height from the budgrafted union.

In order to obtain the farmers' views on planting rubber in the area and to conduct a SWOT analysis, a meeting was organized in Komana village two years after initial planting, i.e. in October 2005. Farmers from both Komana and Helakomana villages participated in this meeting (38 in total). SWOT analysis began with strengths followed by weaknesses, opportunities and threats. Farmers were initially made aware of a SWOT analysis using a flip chart. The farmers were thereafter encouraged to draw up their own lists. Thereafter, farmers were guided to rank the items under each category based on the importance as perceived by them. In instances where a common agreement could not be obtained, the decision on the ranking position was taken considering the preference of the majority. Once the ranking had been completed, the ranking positions were quantified with marks given by the farmers. In this process, 200 marks were given to the top rank and then the marks under each category were allocated by the farmers considering the relative importance. When farmers proposed wide ranging levels of marks for an item, the average values were taken.

The relative distribution of the importance of each item under the four different categories of SWOT was also assessed. The farmers categorized (as they perceived) each item in the list as high, medium or low. The percentage values for the categories were calculated.

At the end of the SWOT analysis, farmers collectively mentioned their immediate needs for successful cultivation of rubber. In addition, information on land distribution and the livelihood of people in both villages falling under Helakomana Gramasevaka Division was collected from the key informants including the Grama Niladhari.

\section{RESULTS}

\section{Climatic suitability and social acceptability}

The province includes two major climatic zones, namely Low Country Intermediate (referred as IL2) and Low Country Dry (referred as DL2), representing 17\% and $78 \%$ of the land area, respectively (Figure 1). Due to the

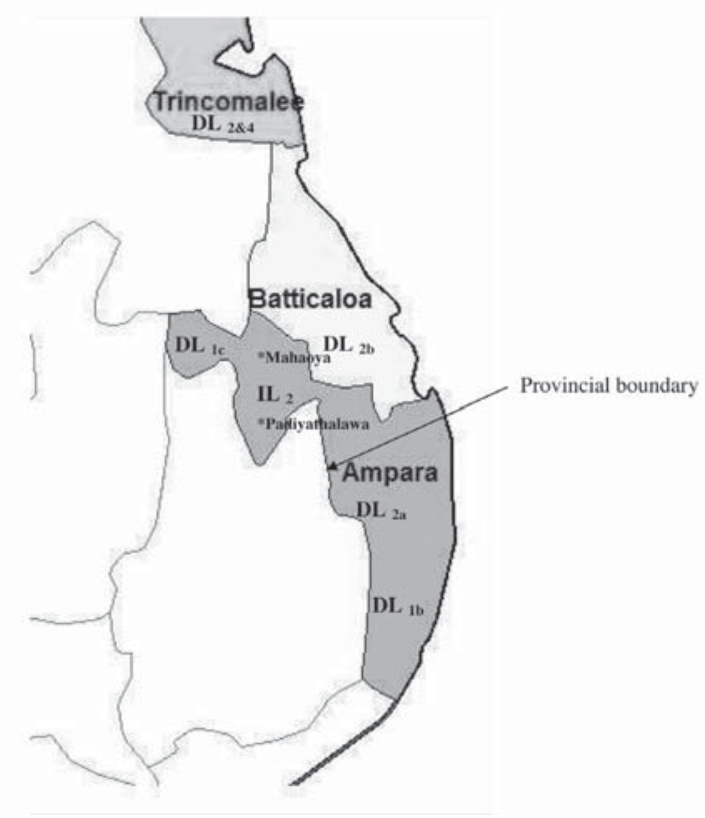

Figure 1: Map showing the distribution of agroclimatic zones in the Eastern Province 
higher level of rainfall over the DL2, IL2 appeared to be more appropriate for initial planting of rubber. Upland soil types recorded in the area were reddish brown earth (RBE), immature brown loam (IBL) \& non calsic brown loams (NCB) (Panabokke, 1996;DOA, 2003b). Among soil types, IBL and RBE were considered to be more suitable than NCB since the NCB was coarser than the rest hence might get dried quickly after rain. The soil $\mathrm{pH}$ in sites selected for initial cultivation was between 5.3 and 6.3 whilst the level of organic carbon in these soils was in the range of 0.4 to 1.1 (Table 2). The area under the IL2 was within the Ampara District and covered two administrative regions (Pradeshiya Sabhas), Padiyatalawa and Maha Oya. Padiyatalawa owned 75 villages in 20 Gramasevaka (GS) divisions with a population of 16,970 in 3970 families, whilst ca. 30,000 people were living in 90 villages of 17 GS divisions in Maha Oya (personal communication with the relevant Divisional Secretaries).

Table 2: Soil properties in Komana village in Eastern Province

\begin{tabular}{lc}
\hline Soil property & Range \\
\hline $\mathrm{pH}$ & $5.3-6.3$ \\
Organic Carbon \% & $0.45-1.07$ \\
Texture & loamy sand to sandy loam \\
\hline
\end{tabular}

According to the Divisional Secretaries of both Pradeshiya Sabhas, ca. $95 \%$ of the community members were full-time farmers and the majority cultivated seasonal crops such as cowpea, maize, pumpkin, upland paddy, chilies and banana under rain-fed conditions. Irrigation techniques were used by few farmers for the cultivation of banana and tobacco. The main perennial crops grown included lime, orange, mango, teak and coconut. On average, each family owned ca. 3-4 acres of land. Most of the land available for cultivation appeared to be crown land that had been used for shifting cultivation. Farmers grew crops on these lands with or without land-permits issued by the government. Nevertheless, farmers were not allowed to clear land with forest cover. Both DSs were willing to issue land permits to grow rubber on land abandoned after shifting cultivation. To qualify for the rubber subsidy programme, farmers had to possess a land certificate, which would prevent administrative problems.

\section{Crop establishment}

In general, field establishment of rubber plants was successful with a mean survival rate of $75 \%$ for all sites (Table 3). The survival rate in Helakomana was lower than that of Komana as in three out of six sites in Helakomana village the percentage survival was $50 \%$ or lower. In Komana, only one site (out of eight) recorded a survival rate below $70 \%$.

Table 3: Details of the establishment and growth of rubber in the Eastern Province

\begin{tabular}{ccccccc}
\hline $\begin{array}{c}\text { Small } \\
\text { holdings } \\
\text { no. }\end{array}$ & Village & $\begin{array}{c}\text { Year of } \\
\text { planting }\end{array}$ & $\begin{array}{c}\text { Number of } \\
\text { plants at } \\
\text { the } \\
\text { beginning }\end{array}$ & $\begin{array}{c}\text { Number of } \\
\text { trees } \\
\text { available as at } \\
\text { May 2006 }\end{array}$ & $\begin{array}{c}\text { Mean girth } \\
\text { as at May } \\
2006 \\
(\mathrm{~cm})\end{array}$ & $\begin{array}{c}\text { Mean rate } \\
\text { of girth } \\
\text { expansion } \\
(\mathrm{cm} / \text { year) }\end{array}$ \\
\hline 01 & Komana & 2003 & 200 & 200 & 17.95 & 7.69 \\
02 & Komana & 2003 & 225 & 200 & 14.76 & 6.42 \\
03 & Komana & 2004 & 400 & 400 & 13.06 & 10.45 \\
04 & Komana & 2004 & 225 & 100 & 10.40 & 8.32 \\
05 & Komana & 2004 & 340 & 300 & 10.88 & 8.70 \\
06 & Komana & 2005 & 100 & 100 & Not recorded & - \\
07 & Komana & 2005 & 223 & 200 & Not recorded & - \\
08 & Komana & 2005 & 450 & 310 & Not recorded & - \\
09 & Hela Komana & 2004 & 225 & 200 & 8.90 & 7.12 \\
10 & Hela Komana & 2004 & 225 & 200 & 6.18 & 5.74 \\
11 & Hela Komana & 2004 & 225 & 102 & 6.23 & 4.98 \\
12 & Hela Komana & 2005 & 225 & 225 & 86 & Not recorded \\
13 & Hela Komana & 2005 & 2005 & 450 & Not recorded & Not recorded \\
14 & Hela Komana & 225 & & - \\
\hline
\end{tabular}

Note: Girth was measured at $1.2 \mathrm{~m}$ height of the trunk as in 2006 
Table 4: Summary of SWOT analysis conducted in Komana village, Padiyatalawa in the Eastern Province; (a) strengths, (b) weaknesses, (c) opportunities and (d) threats

(a)

\begin{tabular}{llllll}
\hline \multirow{2}{*}{ Rank } & Strength & Value & \multicolumn{3}{c}{ Relative distribution (\%) } \\
& & & Low & Medium & High \\
\hline & & & & & \\
1 & Land availability & 200 & 0 & 29.7 & 70.3 \\
2 & Farmers' interest & 175 & 0 & 0 & 100 \\
3 & Suitable environment & 160 & 2.7 & 97.3 & 0 \\
4 & Soil fertility & 145 & 0 & 67.6 & 32.4 \\
5 & Experience in farming & 130 & 0 & 2.7 & 97.3 \\
6 & Labour availability & 120 & 8.1 & 13.5 & 78.4 \\
7 & Interfamily relationships & 105 & 0 & 70.3 & 29.7 \\
8 & Ability afford the initial investment & 75 & 63.2 & 36.8 & 0 \\
9 & Rubber society & 60 & 0 & 0 & 100 \\
\hline
\end{tabular}

(b)

\begin{tabular}{clllll}
\hline \multirow{2}{*}{ Rank } & Weakness & Value & \multicolumn{2}{c}{ Relative distribution (\%) } \\
& & & Low & Medium & High \\
\hline & & & & & \\
1 & Lack of knowledge & 200 & 0 & 23.5 & 76.5 \\
2 & Problems on land ownership & 165 & 18.4 & 2.6 & 79 \\
3 & Lack of finances assets & 150 & 0 & 63.9 & 36.1 \\
4 & Poor roads & 130 & 41.9 & 54.8 & 3.3 \\
5 & Distinct dry period & 125 & 5.4 & 67.6 & 27 \\
6 & Seasonal demand for labour & 100 & 22.2 & 77.8 & 0 \\
\hline
\end{tabular}

(c)

\begin{tabular}{clllll}
\hline Rank & Opportunity & Value & \multicolumn{2}{c}{ Relative distribution (\%) } \\
& & & Low & Medium & High \\
\hline 1 & Extension service & 200 & 8.3 & 75 & 16.7 \\
2 & Rubber subsidy scheme & 140 & 0 & 94.1 & 5.9 \\
3 & Ability to confirm the land ownership & 75 & 0 & 67.6 & 32.4 \\
4 & Opening to new income generating & 45 & 0 & 77.1 & 22.9 \\
& activities such as raw rubber processing & & & & \\
\hline
\end{tabular}

(d)

\begin{tabular}{clllll}
\hline Rank & Threat & Value & \multicolumn{2}{c}{ Relative distribution (\%) } \\
& & & Low & Medium & High \\
\hline & & & & 60.5 & 39.5 \\
2 & Droughts & 200 & 0 & 41.2 & 14.7 \\
3 & Diseases & 180 & 44.1 & 41.2 & 2.8 \\
4 & Cyclones & 150 & 0 & 97.2 & 0 \\
5 & Drop in rubber price & 135 & 41.2 & 58.8 & 3.2 \\
\hline
\end{tabular}

Note: A value of 200 was given to the topmost item and then others have been valued considering the relative importance. Relative distribution refers to the percentage farmers falling into the three categories given. 
On an average the annual rate of girth expansion of rubber in all sites of smallholdings was $7.44 \mathrm{~cm}$ (Table 3). Trees planted in 2003 showed a growth of $7.11 \mathrm{~cm} /$ year whilst those planted in 2004 showed a growth of $7.55 \mathrm{~cm} /$ year.

\section{SWOT analysis}

Land availability in the area was the highest strength for the rubber cultivation with ca. $70 \%$ farmers belonging to the high land available category (Table 4). The second highest strength was the farmers' interest for rubber cultivation. All farmers who attended the meeting were highly interested in planting rubber. Environment and soil fertility respectively were considered to be moderately suitable by over $97 \%$ and $67 \%$ of the farmers. Although farming experience was in fifth position with a value $35 \%$ less than the highest position of the list of strengths a clear majority $(97.3 \%)$ of farmers claimed to have high level of experience. A similar pattern was shown for labour availability with $78.4 \%$ of farmers listing it in the high category. According to the majority of farmers, interfamilial relationships facilitated rubber cultivation at a moderate level and ca. $30 \%$ of farmers listed it in a high position. Although farmers had an opportunity to obtain the benefits of the rubber society its importance as a strength was identified as $70 \%$ less than the highest.

Only six weaknesses were identified in the study. Lack of knowledge on rubber cultivation was identified to be the most critical issue by most farmers. None of the farmers identified this item in a high position. Problems associated with land ownership were limited after obtaining state clearance for rubber cultivation.
This was a serious problem for $79 \%$ of farmers. Lack of finances was the third identified weakness by all farmers and was categorized as low or moderate. The importance of the lack of finances was within $25 \%$ of the value for the highest weakness. Road conditions were identified as satisfactory by only $3.3 \%$ farmers. Dry periods were identified as a problem by over $90 \%$ of the farmers either at medium or high level. Seasonal demand for labour for cultivation activities of other crops could also limit the labour supply for rubber. However, this was identified only as a moderate level problem by the majority.

Out of the four items listed as opportunities, farmers perceived that expansion of the rubber extension service in the region would be the principal opportunity and this was followed by financial benefits from the rubber subsidy scheme. The ability to obtain land ownership with the cultivation of rubber and chances for new income generating activities related to rubber processing were identified as the third and fourth items. Their relative values were over $60 \%$ and $75 \%$ lower than the highest position in the list.

Five threats were identified. Unexpected droughts were ranked as the highest possible threat to the rubber cultivation. Approximately $40 \%$ farmers considered it to be in the high risk category. Diseases were ranked in the second place, however ca. $44 \%$ farmers perceived this as a low level threat. Cyclones were considered to be a medium level threat by most of the farmers. Sudden drop in rubber price and attacks by wild animals were also threats to rubber cultivation but were ranked at the bottom of the list.

Table 5: Land use and population statistics in Helakomana Grama Niladhari division

\begin{tabular}{lclc}
\hline Land use pattern & Extent (ac) & Distribution of population & Numbers \\
\hline $\begin{array}{l}\text { Home garden } \\
\text { Rubber }\end{array}$ & 440 & Total Population-Male & 470 \\
Paddy & 71 & Total Population-Female & 458 \\
$\begin{array}{l}\text { Perennial crops } \\
\text { other than rubber }\end{array}$ & 70 & Number of families & 224 \\
Non permanent Crop & 610 & Number of families engaged in & 73 \\
& & rubber cultivation \\
Forest land & 600 & Number of families engaged in & 121 \\
Barren lands suitable & farming only (with no rubber) & \\
for rubber & 400 & Number of families engaged in & 30 \\
& & other jobs with farming(with \\
Barren lands not & 200 & no rubber) \\
suitable for rubber & & \\
\hline
\end{tabular}


There were some special requests made by the farmers during the SWOT analysis. Among the requests were mechanized bush cutters to facilitate initial land clearing, an extension office to obtain advice and guidance on rubber, and supply of rubber plants and fertilizer on time.

\section{Land use pattern and livelihood of people in Helakomana GS division}

Land use pattern in Helakomana GS division was dominated by forests, short-term crops and home garden crops (Table 5). In this village $4.5 \%$ of uplands are cultivated with rubber. Cultivation of permanent crops was confined to 166 hectares of land. A large extent (ca. $600 \mathrm{ac}$ ) of uncultivated lands was found in this village and of that $66 \%$ appeared to be suitable for rubber cultivation.

All members of the households were engaged in farming activities with the majority on full-time basis. Those engaged in rubber cultivation amounted to $33 \%$. The percentage of families engaged in off-farm activities was $13 \%$ (Table 5 ).

\section{DISCUSSION}

The area under IL2, (Figure 1) of the Eastern Province was found to be the suitable region for initial cultivation due to the fact that the amount and the distribution of rainfall in this area were quite similar to those of the rubber growing region in Monaragala district (Panabokke, 1996; DOA, 2003b). Two soil types, i.e. IBL and RBE, which are predominant in the Intermediate Zone, are also suitable for rubber. The soil $\mathrm{pH}$ in these areas appeared to be at the high level of the optimum range for the growth of rubber. The organic carbon in these soils appeared to be low, which could be adjusted by applying organic materials. Addition of organic matter will not only improve soil fertility but also help to reduce the potential moisture stress on rubber plants during the dry spells through the improvement in soil structure. Basically, the available lands for rubber cultivation in the area were fallow after several cultivation cycles of seasonal crops, which would have affected the soil structure.

Growth of rubber was satisfactory in most sites indicating the agronomic suitability of the crop to the area concerned. Rubber is a completely new crop to this area, and the high level of casualties in some smallholdings could mainly be attributed to lack of knowledge. Although a workshop on planting was conducted, it had not been adequate for farmers to get a sound working knowledge on planting and upkeep of rubber. Farmers would need frequent advice by knowledgeable extension personnel to provide on-site guidance on scientifrc cultivation practices. Fertilizer was not applied on time and only one application was made although the recommendation is for four applications per year. Despite these constraints, the overall growth of rubber was of an acceptable standard. Since recommendations on fertilizer application for rubber were based on field experiments carried out in the Wet Zone of the country, a detailed assessment on soil nutrients and their availability for rubber cultivation is required in this region.

The rainfall distribution of IL2 includes a dry period from March to September with some intermittent rains in April/May. In order to minimize the impact of dry spells on plant growth, well-grown poly-bagged plants with a good root system i.e. plants raised through the young budding technique (Seneviratne, 2001) should be used for planting together with other cultural practices such as deep planting and mulching. Rice straw would be more suitable mulching material due to the high potassium content, which helps to alleviate any moisture stress on rubber plants (Samarappuli et al., 1993). Further, planting with the onset of North-East monsoon provides a sufficient time for plants to establish in the field before the subsequent dry period.

The Intermediate Zone covered a large area that is within the purview of two administrative regions, i.e. Padiyatalawa DS and Maha Oya DS in Ampara District. Farmers in Komana village in the Padiyatalawa DS have shown a deep interest in cultivation of rubber. This interest would help in the successful establishment of rubber and to identify the associated problems and solutions. Under such circumstances, farmers in adjoining villages will develop confidence in the project and will become interested in growing rubber. Even during this study period, farmers in Helakomana (adjoining hamlet coming under the same Garma Niladhari range for Komana village) participated in the rubber cultivation. Therefore, this village can be recognized as the centre for dissemination of rubber cultivation in the region.

Rubber cultivation within the Komana and Helakomana villages (Helakomana GS division) showed an increase with respect to both the number of farmers and the land area cultivated. During the period reported in the present study, ca. 29 ha of rubber had been planted. Uncultivated areas and the lands used for short term crops could also be used for rubber cultivation, making land availability in the Helakomana GS division that exceeds 400 ha. Setting a realistic target of $75 \%$ of these lands 300 ha of rubber can be planted in this 
GS division. Assuming a similar situation in other GS divisions, rubber could be cultivated in over 10,000 ha in the villages (37 GS divisions) falling within the purview of the Padiyatalawa DS and the Maha Oya DS (mostly of the Intermediate Zone) of the Eastern Province. Land availability was recognized as the greatest strength by the farmers in Helakomana GS division with an average of 3.5 ha of upland per family. Assuming that 200 families would participate in rubber cultivation, each family may cultivate 1.5 ha of rubber, which is undoubtedly sufficient to sustain their livelihood. In addition to the families engaged in rubber cultivation, other villagers will also benefit directly or indirectly from rubber cultivation.

Farmers in different villages who were interviewed had virtually no knowledge on rubber cultivation. However, these farmers were well experienced and knowledgeable in cultivation practices of other crops. Therefore, with little knowledge given on rubber cultivation, farmers could undertake planting rubber. In order to achieve knowledge transfer, extension programmes on rubber should be included with regard to land preparation and planting techniques in the first instance. Training on other cultural practices such as tapping could be done at a later stage when the necessity arises. Agricultural societies were functioning in some villages and these could be used for transfer of knowledge. Farmers in Komana set up a Rubber Society and once farmers in other villages also recognize the importance of rubber to the region, such farmer societies could be formed in these areas as well. Scientists and the technical staff of the RRISL participated in training programmes on rubber cultivation and the subsidy payments were handled by the (RDD) through their officers in Bibile, Ridheeedimaliyadda. Ridheeedimaliyadda, is ca. $20 \mathrm{~km}$ away from Padiyatalawa and therefore, farmers have recognized the importance of having an extension office in the area concerned. Land availability and the rapid adoption of rubber cultivation by farmers justify the need of an additional extension officer to the area for effective extension and administrative activities.

The farmers in this region were mainly full-time farmers with the majority growing seasonal crops under rain-fed condition. Previous studies in the Intermediate Zone have shown that farmers prefer perennial crops like rubber as a permanent income source (Stirling et al., 2001; Rodrigo, 2003). If rubber is to be grown in these areas, it has to be introduced in the form of a farming system where traditional cropping systems are allowed on same land where rubber is grown to ensure income to farmers until the rubber trees mature. On-farm trials conducted in the present study and in previous studies (Nguema, 1996; Jayasena and Herath, 1986; Azwar et al., 1994 ; Stirling et al., 2001) showed that growing upland paddy, maize, banana and millet with rubber had no negative effect on the growth of rubber. Instead, all studies showed an improved growth of rubber and this has been attributed to the amelioration of the crop microclimate (Rodrigo et al., 2000; Rodrigo et al., 2001). In intercropping, partial shading given to rubber in the early stage of crop development is particularly important when high radiation loads exist in order to alleviate radiation stress on rubber. This has been proven in the Monaragala District, i.e. closest region with similar climatic conditions, with rubber based sugarcane (Rodrigo et al., 2000) and banana (Rodrigo et al., 2003) systems.

In rubber plantations the causal agents of most diseases are the fungi, which are prevalent mostly in humid climates. Therefore, dry areas would provide less disease incidences. Rubber clones commonly used in Sri Lanka have been tested in a similar climate (i.e. in Monaragala) hence, all five clones recommended for the smallholder sector, i.e. RRIC100, RRIC102, RRIC121, RRISL203 and RRISL2001, could be recommended for planting (Attanayaka, 2001). Among those, the clone RRIC121 would be more adaptable as it could produce a better canopy under dry conditions than in wet conditions with less chance for leaf diseases (Attanayaka, 2001).

Being a remote area, infrastructure such as road transport and facilities for accommodation were rather poor in the Eastern Province. This would be a hindrance to implement a project on rubber. Rubber being an industrial crop, the increase in rubber plantations in this region would lead to downstream industries creating more job opportunities to the locals and will ultimately result in improvement of the infrastructure and raise the living standard of poor farmers in the region.

\section{Acknowledgement}

The authors thank the staff of the Rubber Research Institute of Sri Lanka (RRISL) and the Rubber Development Department for providing necessary facilities to conduct this study and Mr. K.B.A. Karunasekera for his assistance in the initial field assessments. Financial assistance for this study was provided jointly by the RRISL and the National Science Foundation of Sri Lanka under grant no. RG/2006/AG14.

\section{REFERENCES}

1. Amaraweera J.A. (1976). History of rubber cultivation for a century. Vidya (Sicence) 10: 5-14. 
2. CARP (1992). Council of Agricultural Research Policy. Status Review Report of Rubber Research Institute of Sri Lanka, Council of Agricultural Research Policy, 114/9, Wijerama Mawatha, Colombo 7.

3. IRSG (2001a). World Rubber Supply/Demand Balance, International Rubber Study Group. Available at www. rubberstudy.com, Accessed December 2006.

4. IRSG (2001b). Rubber Consumption, International Rubber Study Group. Available at www.rubberstudy.com, Accessed December 2006.

5. Central Bank of Sri Lanka (2003a). Annual Report. Central Bank of Sri Lanka, No. 30, Janadhipathi Mawatha, Colombo 1.

6. DOA (2003b). Agro-Ecological Regions of Sri Lanka. Natural Resources Management Centre, Department of Agriculture; Sri Lanka, Sarasavi Mawatha, Peradeniya.

7. IRGS (2004). Rubber Production, International Rubber Study Group. Available at www.rubberstudy.com, Accessed December 2006.

8. Ministry of Plantation Industries (2005). Plantation Sector Statistical Pocket Book, Planning Unit of the Ministry of Plantation Industries, Colombo.

9. Attanayaka D.P.S.T.G.E. (2001). Clones for commercial planting in Sri Lanka. Handbook of Rubber, Volume 1, Agronomy, (eds. L.M.K. Tillekeratne \& A. Nugawela), pp. 86-96. Rubber Research Institute of Sri Lanka, Dartonfield, Agalawatte.

10. Azwar R., Sumarmadji, Haris U. \& Basuki (1994). Intercroppers in smallholder rubber based faming system. Indonesian Agricultural Research and Development Journal 15(3): 45-51.

11. Jayasena W.G. \& Herath H.M.G. (1986). Innovation, receptivity and adoption in rubber smallholding of Sri Lanka. SRRP Research Study, No.71, pp.79-88. Hector Kobbekaduwa Agrarian Research \& Training, Institute 114 Wijerama Mawatha, Colombo 7.

12. Nguema J., Hugot N. \& Enjarlic F. (1996). Rubber and associated food crops in a Central African country. IRRDB Symposium on Farming System Aspects of the Cultivation of Natural Rubber, 12-14 September, 2000
(Hevea brasiliensis), Beruwela Sri Lanka. International Rubber Research and Development Board, Kuala Lumpur, Malayasia, pp. 1-9.

13. Panabokke C.R. (1996). Soils and Agro-Ecological Environments of Sri-Lanka. p. 220. Natural Resources, Energy \& Science Authority, 47/5, Maitland Place, Colombo 7.

14. Rodrigo V.H.L., Nugawela A., Sivanathan A., Witharama W.R.G. \& Jayasinghe W.K. (2000). Rubber cum sugarcane intercropping; a suitable cropping system for the farmers in the intermediate zone of Sri Lanka. Journal of the Rubber Research Institute of Sri Lanka 83: 62-74.

15. Rodrigo V.H.L., Stirling C.M., Teklehaimanot Z. \& Nugawela A. (2001). Intercropping with banana to improve fractional interception and radiation-use efficiency of immature rubber plantations, Field Crops Research 69(3): 237-249.

16. Rodrigo V.H.L., Stirling C.M., ThennakoonS., Senivirathna A.M.W.K. \& Pathirana P.D. (2003). Technology refinement of rubber/banana intercropping using a farmer participatory approach. Tropical Agricultural Research and Extension 6: 77-84.

17. Samarappuli L., Yogaratnam N., Karunadasa P., Mitrasena U. and Hettiarachchi R. (1993). Role of potassium on growth and water relations of rubber plants. Journal of the Rubber Research Institute of Sri Lanka 73: 37-57.

18. Seneviratne P. (2001). Budgrafting techniques and types of planting material. Handbook of Rubber, Volume 1, Agronomy. (Eds. L.M.K. Tillekeratne \& A. Nugawela), pp. 68-85. Rubber Research Institute of Sri Lanka, Dartonfield, Agalawatte.

19. Stirling C.M., Rodrigo V.H.L., Marzano M., Thennakoon S., Sillitoe P., Senivirathna A.M.W.K. \& Sinclair F.L. (2001). Developing rubber-based cropping systems that improve not only latex yield but also the livelihoods of the rural poor; a case study in Sri Lanka. The Rubber International Magazine 3(25): 83-89.

20. Tillekeratne L.M.K., Edirisinghe J.C. \& Herath H.M.L.K. (2002). Trends in rubber processing in Sri Lanka. Bulletin of the Rubber Research Institute of Sri Lanka 44: 44-48. 